\title{
PROGRESS OF GEOGRAPHICAL INFORMATION DATABASE AND HAZARD-MAPPING OF LIQUEFACTION POTENTIAL
}

\author{
Takashi OKIMURA $^{1}$ and Yasuo TANAKA ${ }^{2}$ \\ ${ }^{1}$ Member of JAEE, Professor, Research Center for Urban Safety \& Security, Kobe University, \\ Kobe, Japan, okimura@kobe-u.ac.jp \\ ${ }^{2}$ Member of JAEE, Professor, Research Center for Urban Safety \& Security, Kobe University, \\ Kobe, Japan, ytgeotec@kobe-u.ac.jp
}

\begin{abstract}
During the Kobe Earthquake in 1995, residential buildings and infrastructure were heavily damaged, and extensive liquefaction of ground was also observed. That triggered numerous hazard mitigation studies by gathering geotechnical and geographic information as well as damage records of the earthquake. Especially, processing such data has been making rapid progress, being reflected in mapping of liquefaction potential. This report describes a current state of the studies.
\end{abstract}

Key Words: Jibankun, geotechnical information database engine, GIS database engine, GDBS, bore hole data, one-dimensional dynamic analysis

\section{INTRODUCTION}

After the Kobe Earthquake, Kobe City Government started a study on geotechnical condition in Kobe City, and a research committee was organized in the fall of 1995 to gather geological, geotechnical and geographic information as well as records of damage by the earthquake. Digital records of more than 4000 borehole data in the city were collected and input into a GIS system together with a digital city map of 1/2500 scale that had been produced by the city planning division of Kobe City.

The system is called Jibankun and consists of two engines of software as shown in Fig.1. One of them deals with the borehole data and a software named GDBS performs handling the borehole data, which are composed of borehole log-data as well as many soil testing data, such as standard penetration tests, Atterberg limits, gradation data, etc. The other deals with geographic data, such as digital maps of cities, topographic data, and records of earthquake damage.

By combining the GIS database engine and the geotechnical information database engine, one can draw geological cross sections of ground along any places in the city. Examples of them are shown in Fig.2, 3 and 4. The study on stratigraphy in Kobe City indicates that there is a sharp rise in the bedrock elevation along the foothill of Rokko Mountains. The depth of the unconsolidated deposit in Kobe City is over 1000 meters as illustrated in Fig.4. 


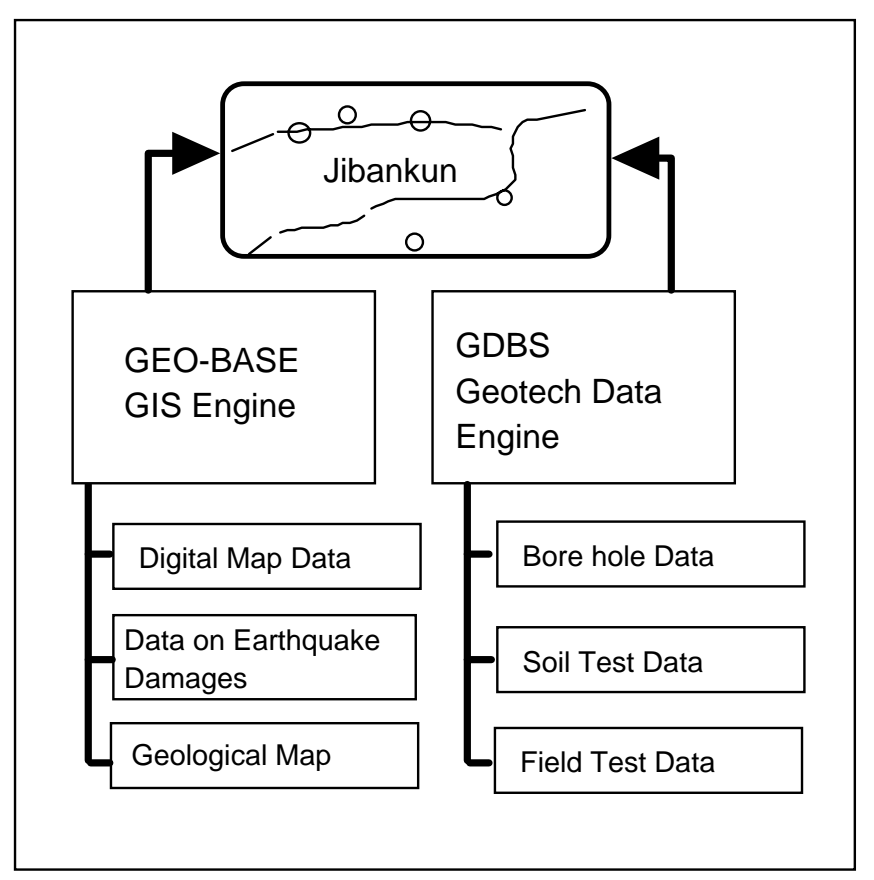

Fig.1 Data flow of two DB engines

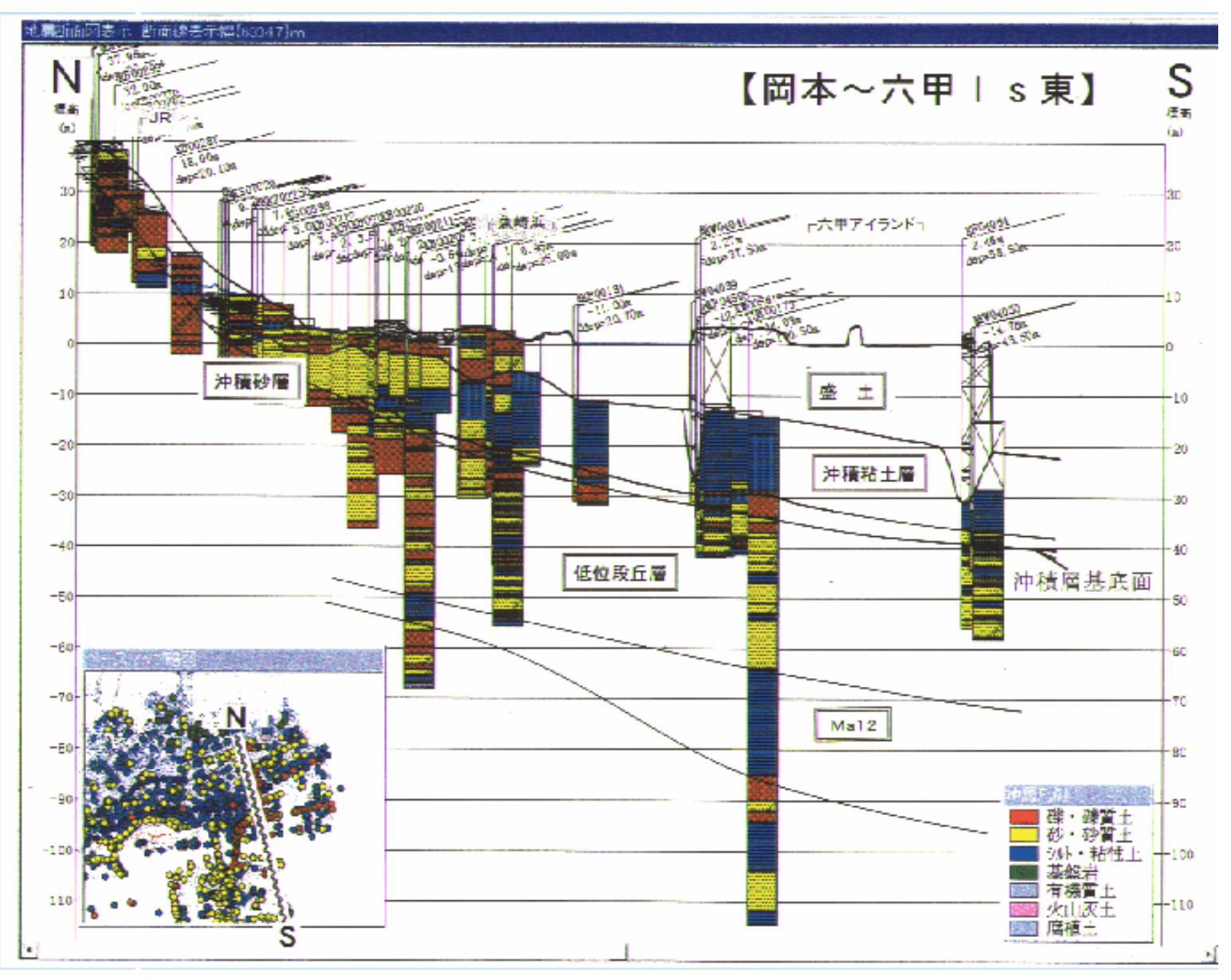

Fig.2 Geological Section at East Kobe 


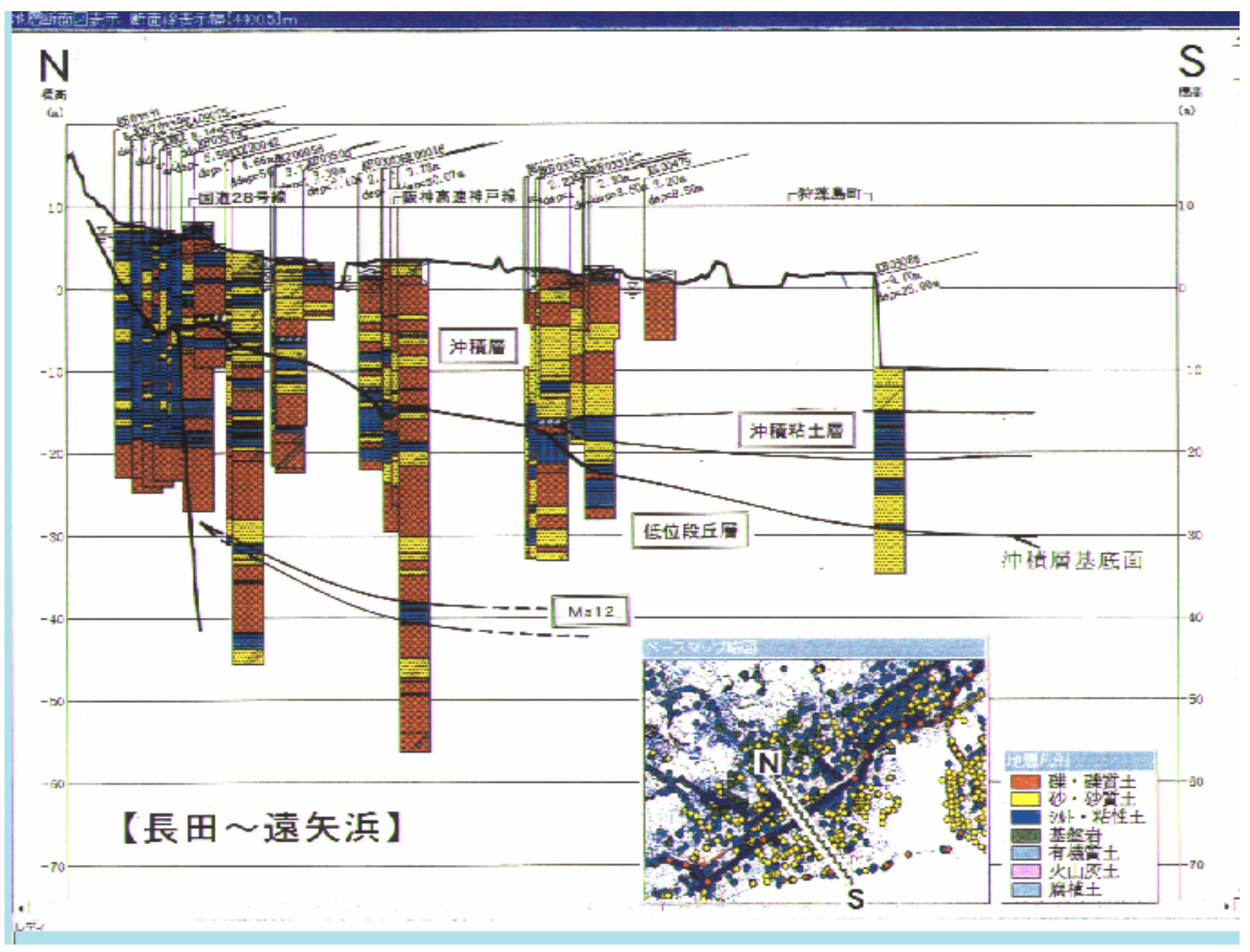

Fig. 3 Geological Section at West Kobe

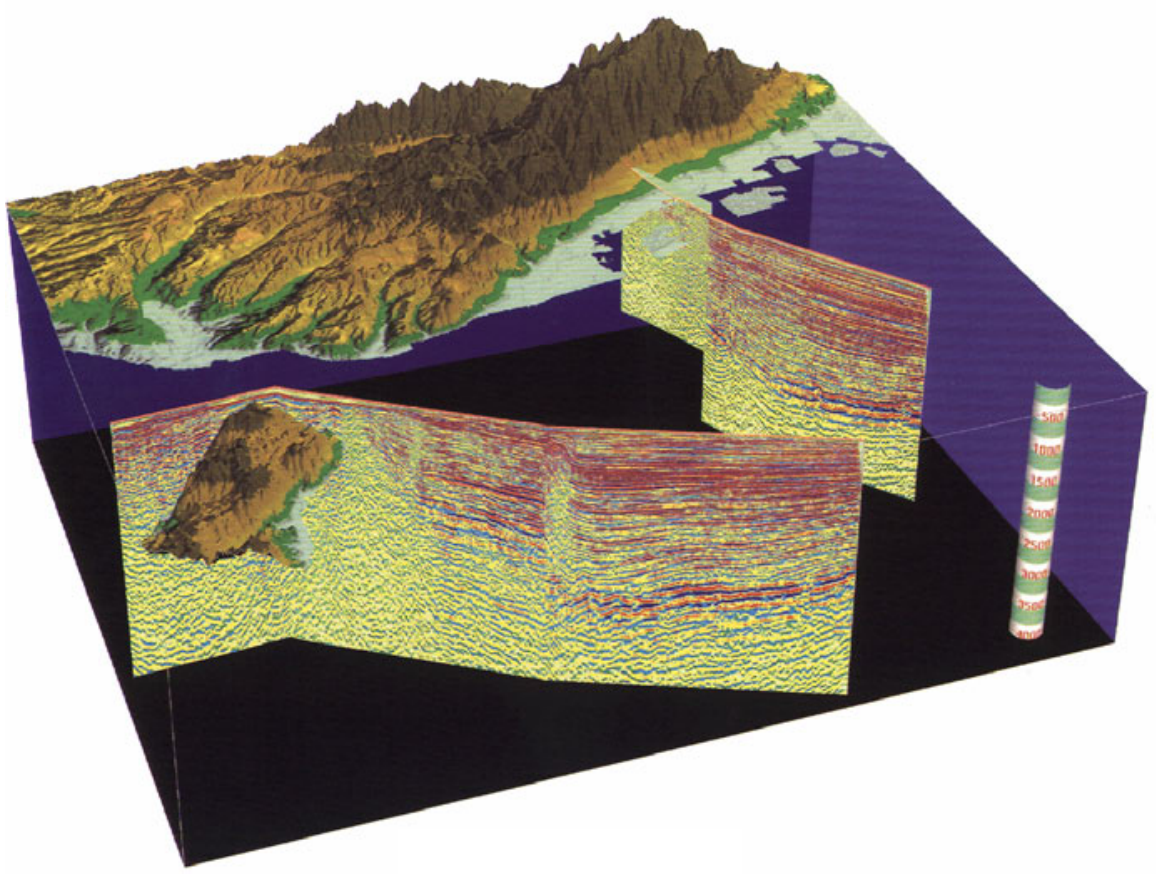

Fig.4 Stratigraphy along the coast of Kobe City 


\section{LIQUEFACTION STUDY}

Based on more than 4000 bore holes, it is also possible to assess liquefaction potential of ground in the city. The method for assessing liquefaction potential is as following. First, the whole area is divided into small elements, 250 meter by 250 meter. For each element of the area, its ground profile is established using borehole data available. Next, one-dimensional dynamic analysis such as SHAKE Analysis is performed by the input of seismic motion at the engineering seismic base. The results of the analysis are then used to determine depth variation of liquefaction resistance of ground, i.e., computations of FL values and PL values.

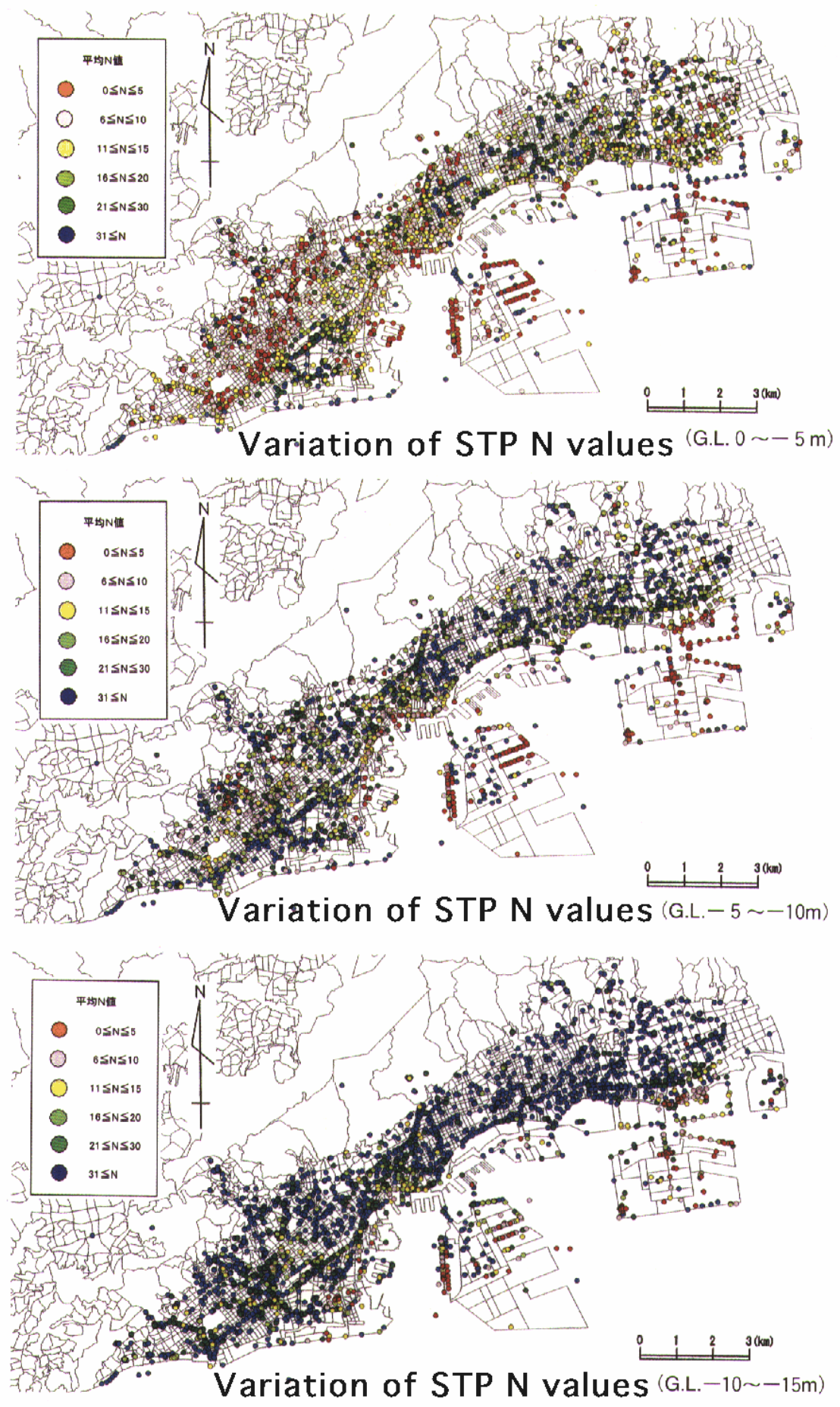

Fig.5 Variation of STP N values at various depths 
The elevation of engineering seismic base may be determined by using the data of standard penetration test results. Fig.5 shows the variations of STP values at three different depths in Kobe City. Evaluation of seismic motion at the engineering seismic base is more difficult, and various approaches are being examined. One approach uses a deterministic method as illustrated in Fig.6.

However, more works seem to be needed in order to finalize a method for computing the seismic motion at the engineering base.

\section{Predietion of eanthquake intensity based on fault location and ground condition}

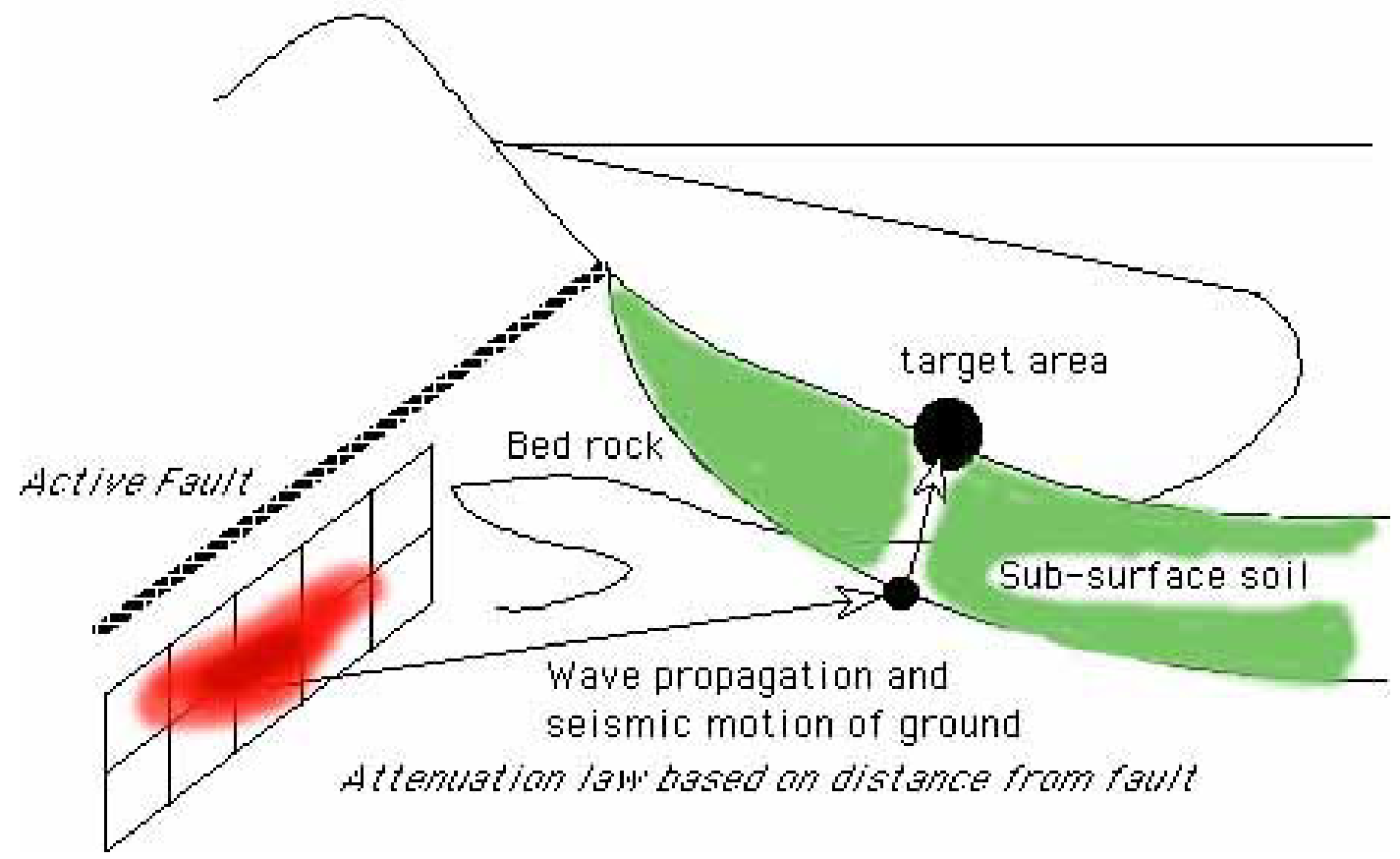

Fig. 6 Deterministic Method for estimating dynamic motion at engineering base

\section{STUDY ON SEISMIC DAMAGE VS STRONG GROUND MOTION}

Many houses were completely or partially damaged by the 1995 Kobe Earthquake, and the areas of intense damage located along the narrow zone at the foothill of Rokko Mountains. In order to study an analytical method for computing the strong ground motion, the information of the damaged-house distribution were input into the GIS database, and the results of various dynamic analyses were examined by checking the agreement between the actual damage and the predicted strong ground motions.

Fig.7 shows the distribution of damaged houses, and in the figure, the degree of damage are examined by computing the weighted value of damage. It is expressed by the following equation:

$$
W_{v d h}=\left(3 C_{d h}+2 H_{d h}+P_{d h}\right) / \Sigma H
$$

in which $W_{v d h}$ : weighted value of damaged houses, $\mathrm{C}_{\mathrm{dh}}$ : completely damaged houses, $\mathrm{H}_{\mathrm{dh}}$ : half damaged houses, $\mathrm{P}_{\mathrm{dh}}$ : partially damaged houses, and $\Sigma \mathrm{H}$ : total number of houses. 


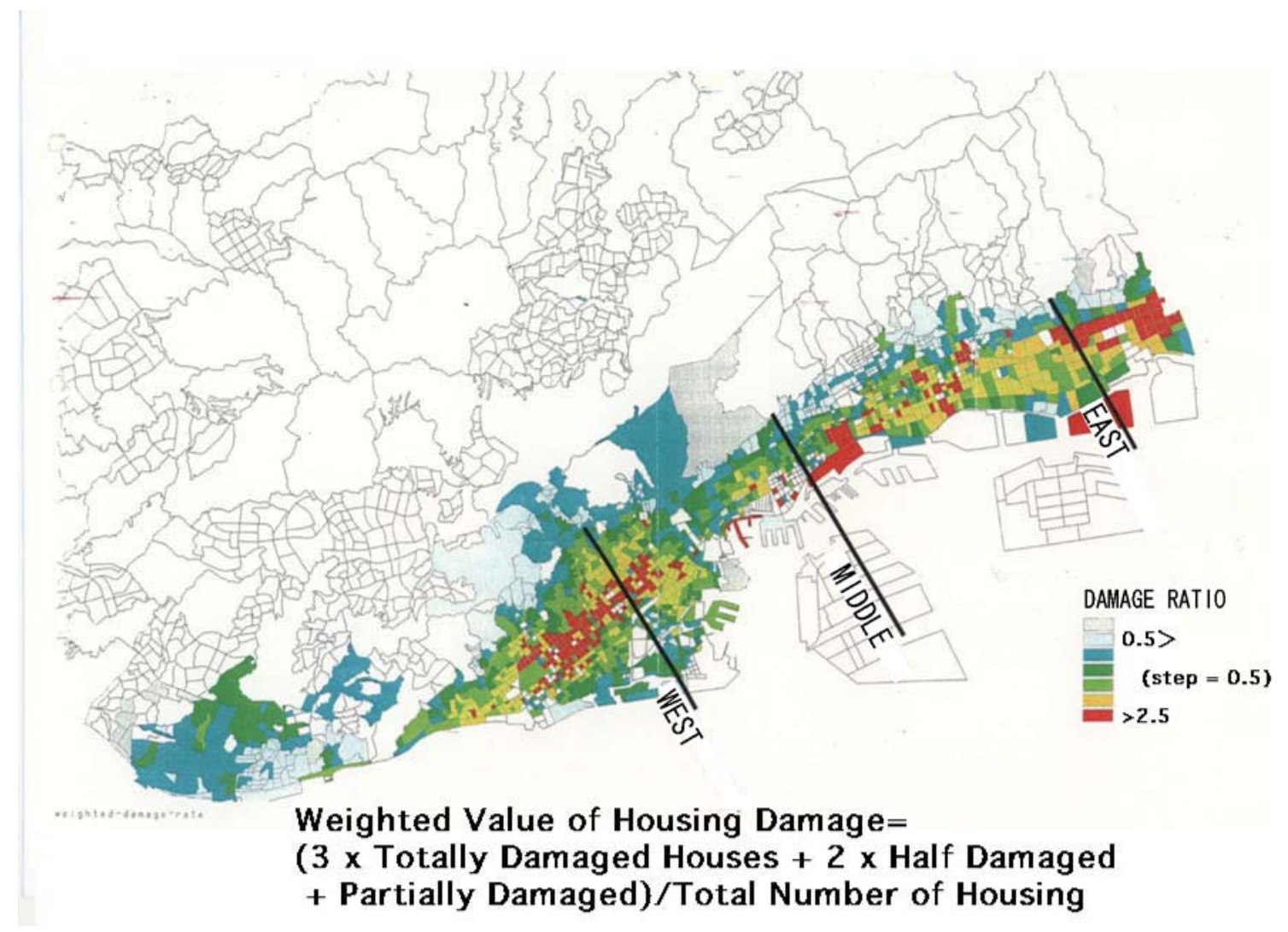

Fig.7 Weighted value of damaged houses

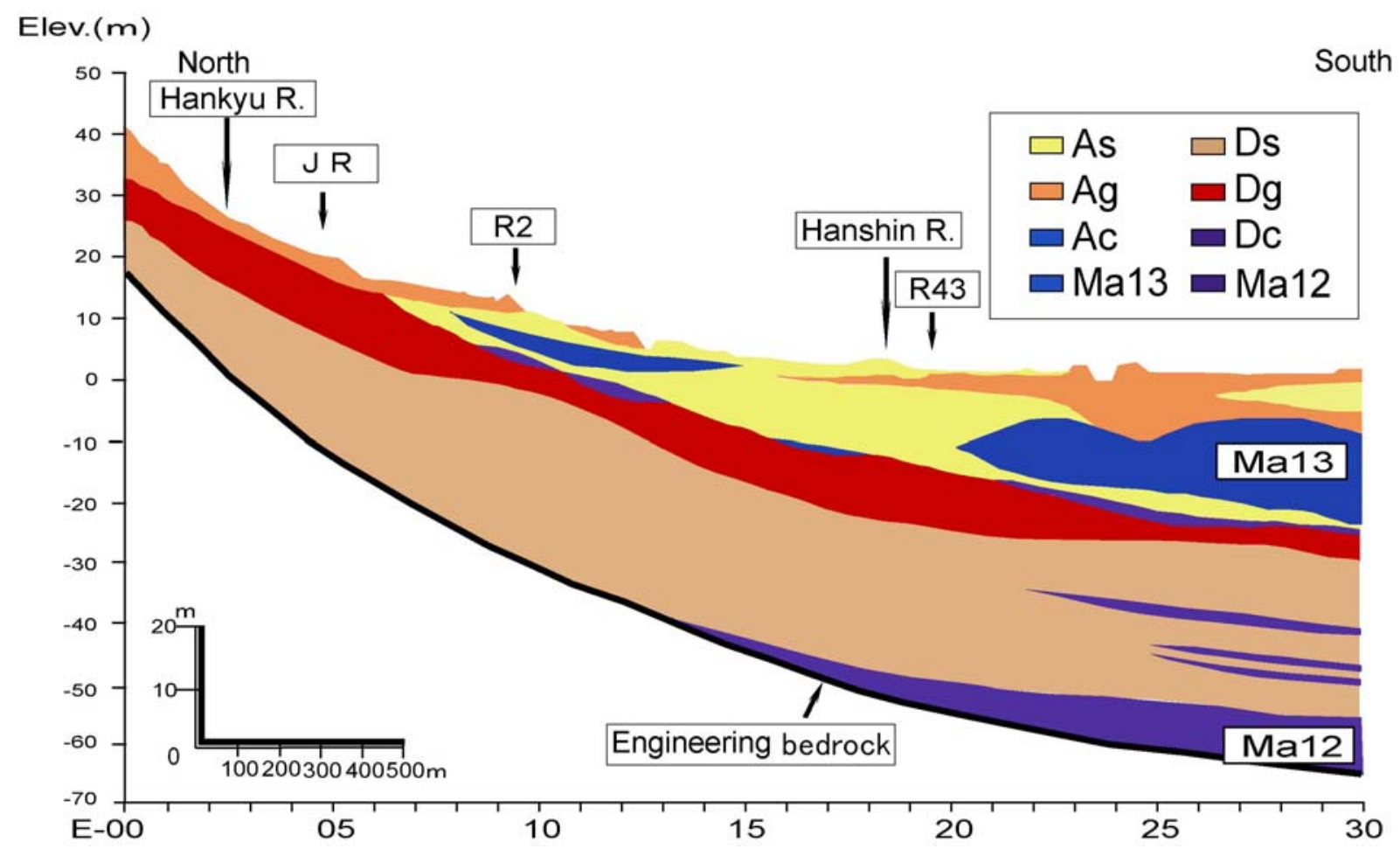

Fig.8 Geological section at East Kobe 
In the study of strong ground motion, a method proposed by Sugito \& Kameda (1985) is used, and at three locations in Kobe City, the variation of seismic motion is compared. The method adopts recorded seismic intensities at various stations and evaluates the seismic motion at the engineering seismic base. The estimated seismic motion is then used to obtain the strong ground motion at the surface through one-dimensional dynamic analysis.

Fig.8 presents one of the geological sections used in the study, and Fig.9 shows the computed strong ground motion at surface. Generally, a rise of the seismic intensity can be seen near the foothill, and the intensity seems to decay towards the seashore.

More works are needed to decide what is the most reliable method for computing the strong ground motion, especially for intra-plate type earthquakes.

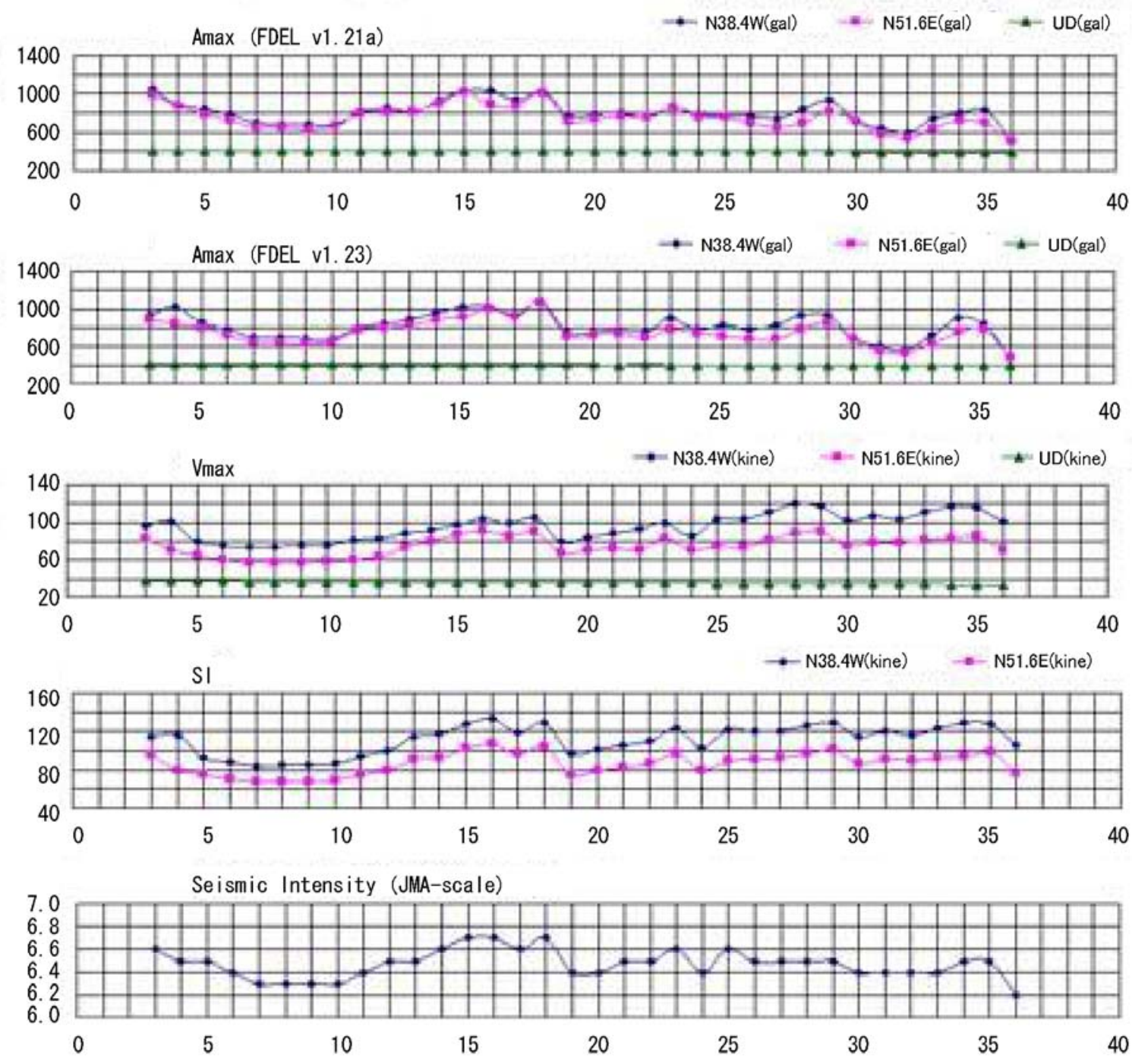

Fig.9 Computed strong ground motion at East Kobe

\section{CONCLUSIONS}

After the Kobe Earthquake, a system called Jibankun was developed, which consists of two softwares. One is based on borehole data and GDBS, and the other is geographic data. This system has made it possible to draw geological cross sections of ground. 
Moreover, numerous borehole data have enabled the assessment of liquefaction potential of ground. The procedures for the assessment are: 1) divide the whole area into small parts, $250 \mathrm{~m} \mathrm{X}$ $250 \mathrm{~m}, 2)$ input the seismic motion at the engineering seismic base for one-dimensional dynamic analysis, and 3) use the result of the analysis to determine the depth variation of liquefaction resistance of ground.

The distribution of damaged houses by the earthquake was also input into the system, and an analytical method for computing the strong ground motion was studied.

\section{ACKNOWLEDGMENT}

The work described in this paper was performed by the liquefaction study team of Research Committee of Kobe Ground. A deep appreciation of the author is due for their efforts and Ms. Taniguchi's editing this paper.

\section{REFERENCE}

Sugito and Kameda (1985). "Prediction of nonstationary earthquake motions on rock surface.” Proc., JSCE, Vol.2, 2, 149-159

(Submitted: July 1, 2004)

(Accepted: July 2, 2004)

Copyright JAEE 